\title{
EVOLUÇÃO DA INTENSIFICAÇÃO DO TRÁFEGO E A INCIDÊNCIA DE ACIDENTES COM TRATORES AGRÍCOLAS NAS VIAS PÚBLICAS BRASILEIRAS
}

\author{
Sabrina Dalla Corte Bellochiol ${ }^{*}$, Airton dos Santos Alonço ${ }^{1}$, Gessieli Possebom ${ }^{1}$, Tiago Gonçalves Lopes ${ }^{1}$ \\ ${ }^{1}$ Departamento de Engenharia Rural, Universidade Federal de Santa Maria, 97105-900, Santa Maria, Brasil.
}

*E-mail: bellochiosabrinad@hotmail.com

\section{RESUMO}

O crescente uso de máquinas agrícolas, especialmente de tratores, na busca pela ampliação da superfície dominável, intensificou também a propensão a acidentes com essas máquinas. Assim, o objetivo desse estudo foi calcular a evolução da quantidade de veículos por quilômetro das rodovias brasileiras, no período de 1970 a 2015 e inter-relacionar com os dados de acidentes envolvendo tratores agrícolas, nas vias públicas. Para esse estudo foi considerada a frota brasileira de veículos convencionais e de tratores nesse período de 45 anos (1970-2015), bem como a extensão em quilômetros, de rodovias brasileiras. No último ano analisado (2015), foi observado um total de mais de 1,72 milhões de quilômetros de vias e 43,5 milhões de unidades de veículos em circulação. Se comparado aos 1,13 milhões de quilômetros e 2,5 milhões de veículos, em 1970, o crescimento de 52,21\% e 16,8 vezes, respectivamente, demonstram a acentuada intensificação do tráfego. Em concomitante, também se elevou a circulação de tratores em vias públicas, o que aliado a velocidade das vias, bem como o tipo e a largura das mesmas, elevaram, por sua vez, a ocorrência de acidentes. Dentre os acidentes, as colisões traseiras em tratores são destaque, com maiores índices evidenciados. Apesar do número de acidentes ser menor, a gravidade dos mesmos apresenta de 5 a 8 vezes mais fatalidades, em comparação aos acidentes com veículos. Assim, a evolução se apresentou positiva, com acréscimo na intensificação do tráfego nas rodovias brasileiras, porém como consequência, há a elevação, também, da ocorrência de acidentes com tratores nesta condição.

Palavras-chave: Mecanização. Densidade do tráfego. Veículos. Iluminação e sinalização. Colisões.

\section{Introdução}

Os acidentes de trânsito estão entre as dez principais causas de mortes no mundo [1]. Proporcionalmente à população, o trânsito brasileiro, quando comparado ao dos países desenvolvidos, apresenta 2,5 e 3,7 vezes mais fatalidades do que o norte americano e o europeu, respectivamente. Este fato leva a uma grande preocupação em relação ao aumento dos índices de motorização dos países pobres e emergentes, sem o equivalente investimento na segurança viária [2]. Citando caso análogo, a União Européia, na última década, tem reforçado a cultura de segurança rodoviária através da criação de novas diretivas, planos e guias de boas práticas [3].

O maquinário agrícola ocupa importante destaque na motorização brasileira. A crescente demanda por alimentos e a consequente necessidade de máxima produtividade na agricultura, impulsionaram o uso de máquinas agrícolas, especialmente de tratores. Aliado a economia atual, o Brasil é o quarto maior mercado de tratores agrícolas no mundo, atrás de países como Índia, China e Estados Unidos [4].

O trator assume o papel central nas operações agrícolas, sendo caracterizado como a principal fonte de potência, especialmente nas operações que requerem força, tração e suporte [5]. Corroborando seu elevado uso, os tratores representam mais de $80 \%$ do total das vendas internas de máquinas agrícolas e rodoviárias no Brasil. Há maior representatividade de vendas nas regiões Sul e Sudeste, com $70 \%$ do total, com destaque para o estado de São Paulo, com 22\% de aquisição em 2017 [6].

Apesar de concebidos como força de trabalho e projetados para a operação em atividades agrícolas, essas máquinas necessitam realizar deslocamentos de uma área para outra, fazendo o uso não só de estradas da propriedade, como também de vias públicas [7-13]. Entretanto, quando os tratores agrícolas trafegam nessas vias, caracterizam-se como veículos lentos por trafegarem, geralmente, a uma velocidade entre 15 $\mathrm{km} \cdot \mathrm{h}^{-1}$ e $20 \mathrm{~km} \cdot \mathrm{h}^{-1}$, muito inferior à velocidade atingida por outros veículos [9]. No Brasil, onde não existe sinalização regulamentadora, a velocidade máxima das vias urbanas varia de 30 km.h-1, em vias locais; a $80 \mathrm{~km} . \mathrm{h}-1$, em vias de trânsito rápido. No caso das vias rurais, a velocidade máxima varia de 60 $\mathrm{km} . \mathrm{h}-1$ nas estradas, $100 \mathrm{~km} . \mathrm{h}-1$ em rodovias de pista simples e $110 \mathrm{~km} . \mathrm{h}-1$ em rodovias de pista dupla [14].

O crescente uso dos tratores agrícolas em vias públicas, bem como o de tratores com maior tempo de uso, são fatores que contribuem para maiores probabilidades de lesões severas e fatalidades [7]. Um exemplo disso pode ser observado em estudo 
desenvolvido em Portugal, no qual demostraram oito vezes mais fatalidades nos acidentes com tratores no tráfego, comparados aos automóveis [12]. Segundo os mesmos autores, essas máquinas antigas não possuíam itens de segurança e proteção adequados, os quais conferem características singulares e garantem o bem-estar de quem as opera.

Assim, o objetivo deste estudo foi calcular a evolução da quantidade de veículos por quilômetro nas rodovias brasileiras no período de 1970 a 2015 e inter-relacionar este dado com estudos científicos sobre os acidentes envolvendo tratores agrícolas nas vias públicas.

\section{Metodologia}

\subsection{Frota brasileira de veículos}

Os dados relativos à frota brasileira de veículos foram adquiridos no trabalho de Guimarães; Lee [15], que tomam como base, informações do SINDIPEÇAS, no ano de 2009 e compreendem os anos de 1970 a 2008 . Referente ao período de 2009 a 2016, os dados foram extraídos diretamente do relatório SINDIPEÇAS [16].

Esta composição considera automóveis, veículos comerciais leves, caminhões e ônibus.

\subsection{Frota brasileira de tratores}

Foi considerado o estudo de Bellochio et al., [17] onde afirmam que a frota brasileira de tratores é constituída por 944.438 unidades. Os autores contemplaram o período de 1960 a 2016, com vistas à tratores com até 30 anos de uso.

\subsection{Rodovias brasileiras}

A quantidade de quilômetros de rodovias brasileiras foi obtida por meio da análise dos dados referentes aos anuários estatísticos do extinto Grupo Executivo de Integração da Política de Transportes (GEIPOT) [18], compreendidos entre o período de 1977 a 2001. Na sequência, foram adquiridos os dados de 2010 e 2015, divulgados pelo anuário da Confederação Nacional de Transporte [19].

\subsection{Densidade do tráfego de veículos (número de veículos por quilômetro \\ É possível relacionar a intensificação do uso das vias e o} número crescente de automóveis em circulação no país, resultando no índice de densidade do tráfego de veículos por quilômetro.

Assim, foi estabelecido o cálculo para o período de 1970 a 2015, através da razão entre o número total de quilômetros de rodovias brasileiras e a soma da frota de veículos e de tratores disponíveis no Brasil.
O índice apresenta uma relação positiva à intensificação do uso das vias, sendo que, quando a mecanização agrícola é intensificada e o número de veículos licenciados é crescente, ocorre aumento no valor do índice de densidade do tráfego de veículos.

\section{Resultados e discussões}

Na Figura 1 é apresentada a evolução da extensão da rede rodoviária brasileira, em quilômetros. Pode-se observar que o último ano de levantamento (2015) totalizou mais de 1,72 milhão de quilômetros de vias, sendo $7 \%$ federais, $15 \%$ estaduais e $78 \%$ municipais [19]. Quando comparado aos 1.130.395 quilômetros de vias do ano de 1970, houve crescimento de 52,21\%, ao longo dos 45 anos [18-22], demonstrando uma taxa anual de expansão menor, quando comparada a estrutura já instalada.

Segundo Pereira; Lessa [22], ocorreu forte relação na expansão da infraestrutura rodoviária brasileira, em meados da década de 1950, com as necessidades dos complexos industriais automobilísticos que se instalaram no país. Esta relação influenciou a política de transporte brasileira, que centralizou os investimentos no modal rodoviário em detrimento aos outros modais de transportes, tornando o sistema de rodovias, como o principal meio de transporte de cargas e de passageiros no tráfego do país.

Com relação à frota brasileira de veículos (automóveis, veículos comerciais leves, caminhões e ônibus), os dados publicados pela ANFAVEA [6] indicam que desde 1993 a quantidade de veículos licenciados anualmente é superior a um milhão e a partir de 2007 se apresenta acima de 2 milhões, sendo que no período entre 2009 e 2014 este número foi maior que 3 milhões de unidades anuais. O pico de veículos licenciados ocorreu no ano de 2012, com mais de 3,8 milhões de unidades. Este valor, ao ser comparado com o apresentado em 1970, é aproximadamente 10 vezes superior. Após o ano de 2012, houve um decréscimo, sendo que em 2016 o total de veículos licenciados ficou próximo a 2 milhões, portanto, ainda superior ao total dos anos anteriores a 2006. Estes dados evidenciam que é cada vez maior o número de veículos circulando nas vias públicas do país.

Os dados da Figura 2, demonstram a representatividade percentual dos veículos e dos tratores. Em relação aos tratores, o percentual de unidades vendidas no Brasil, comparada ao total de veículos, manteve-se superior a 3\% no período de 1970 a 1990, apresentando um pico de 7\% em 1976. A partir de 1990 houve crescimento no número anual de veículos licenciados, porém o número de tratores vendidos anualmente não se demonstrou proporcional, o que reduziu sua representatividade percentual no total, apontando valores inferiores a $2 \%$ nos últimos 12 anos. 

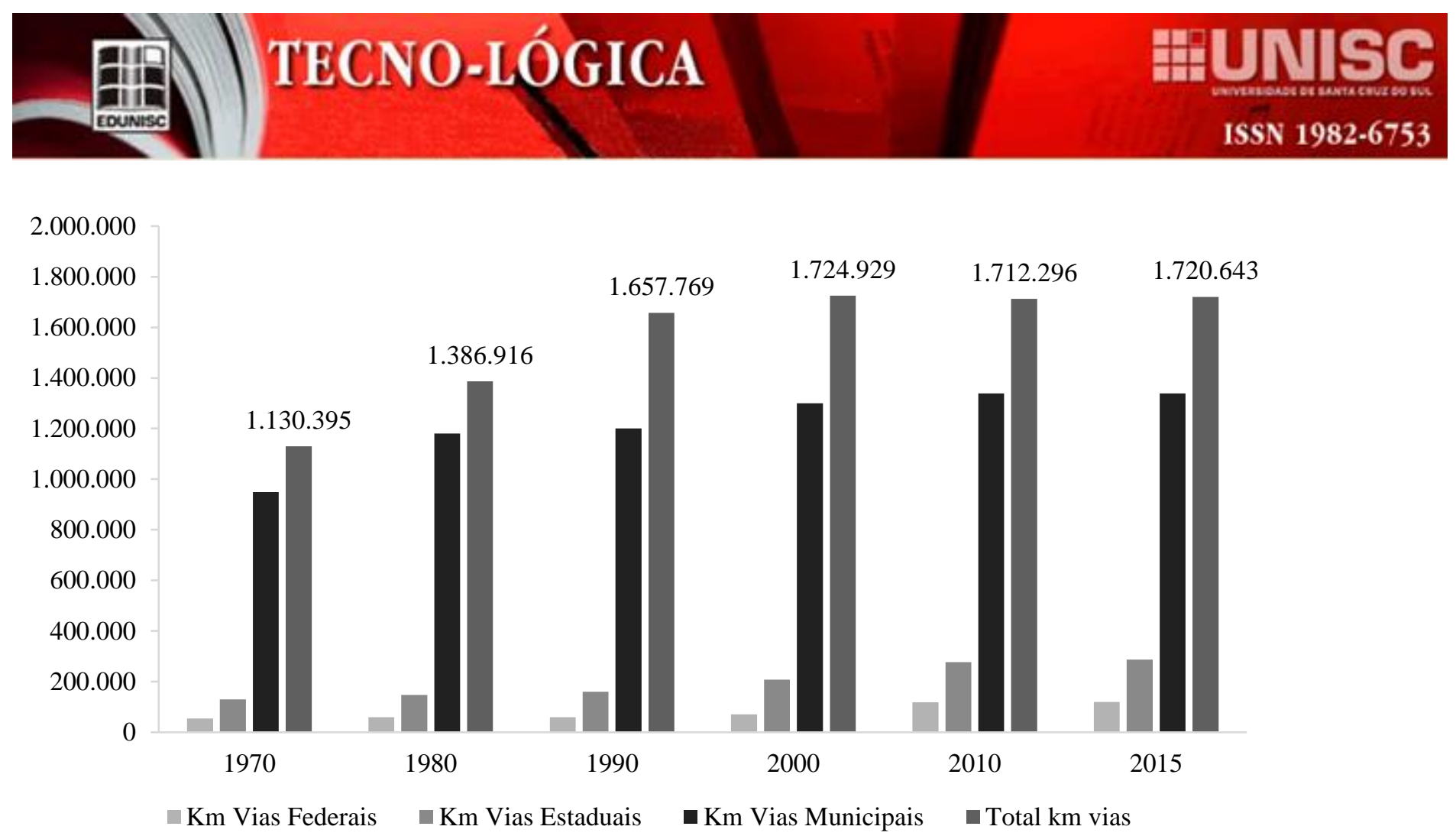

Figura 1 - Evolução da extensão da rede rodoviária brasileira, em quilômetros

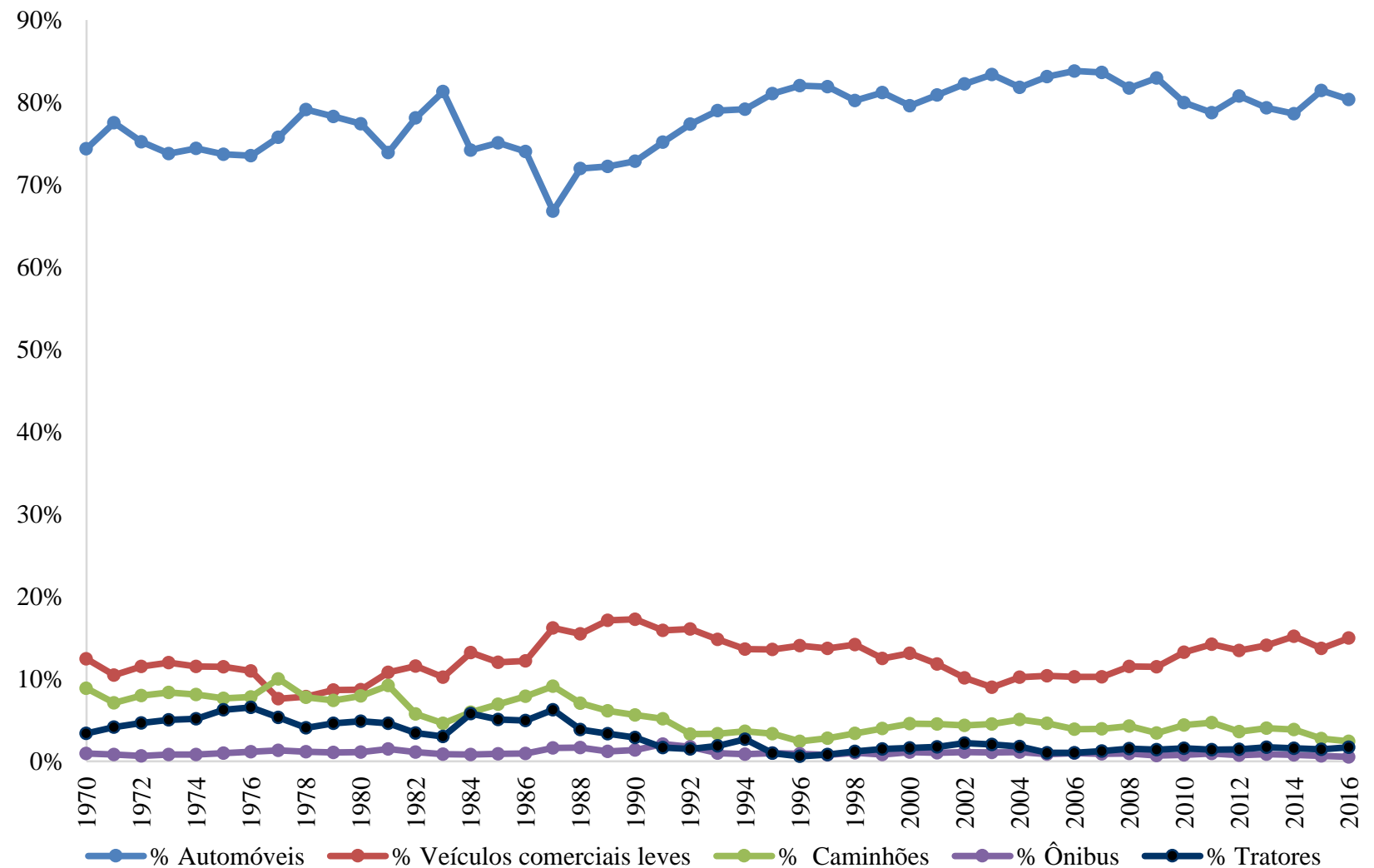

Figura 2 -percentual relativo ao número anual de unidades de automóveis, veículos comerciais leves, caminhões, ônibus e tratores comercializados no Brasil. 
Na Figura 3 é apresentada a composição da frota brasileira de veículos, incluindo o número de tratores, distribuídos por década. No ano de 1970, a frota total correspondia a pouco mais de 2,5 milhões de unidades, sendo composta por $3,4 \%$ de tratores; $78,3 \%$ de automóveis e veículos comerciais leves; $16,4 \%$ de caminhões e 1,9\% de ônibus. Esse cenário passou por mudanças, atingindo 15,8 milhões de unidades em 1993. Desse total, 5,5\% de tratores; $85,5 \%$ de automóveis e veículos comerciais leves; 7,7\% de caminhões e $1,3 \%$ de ônibus. No ano de 2015 , houve o máximo de veículos, totalizando 43,5 milhões de unidades, com 2,2\% de tratores; $92,6 \%$ de automóveis e veículos comerciais leves; 4,3\% de caminhões e $0,9 \%$ de ônibus.

O aumento de 16,8 vezes da frota total de veículos, ao longo dos 45 anos, e de $82,9 \%$ nos últimos 10 anos é perceptível, ressaltando o maior uso de veículos na atualidade. Corroborando o evidenciado, onde além do crescimento populacional de $11 \%$ [2], os incentivos governamentais buscaram impulsionar a geração de empregos através da industrialização do país, por meio do fomento à indústria automotiva [23].
O aumento do número de tratores, especialmente até a década 2000, pode ser uma decorrência da necessidade de elevar a produtividade numa mesma área de trabalho, ou seja, a busca pela ampliação da superfície dominável. Além disso, os incentivos fiscais e o crédito facilitado impulsionaram a renovação da frota, na busca de novas frentes de trabalho, bem como no melhor conforto, segurança aos operadores e compatibilidade com novas tecnologias.

Entretanto, no último ano de estudo (2015), houve redução da porcentagem de tratores, em relação à década de 90. Ou seja, justamente devido a aquisição desses veículos na década de 90 , levou a consequente menor necessidade de maquinário novo nos anos seguintes. Além disso, a necessidade de máquinas mais potentes para a realização de várias atividades em paralelo pode ter influenciado a renovação da frota no sentido de que passou a ter menor número de tratores, porém com maior potência [5]. A queda nas vendas de tratores entre os anos de 1990 e 2006 foi compensada pela elevação da potência das máquinas comercializadas, com aumento da representatividade de tratores na faixa de $100(73,5 \mathrm{~kW})$ a $199 \mathrm{cv}(146,4 \mathrm{~kW})$ [24].

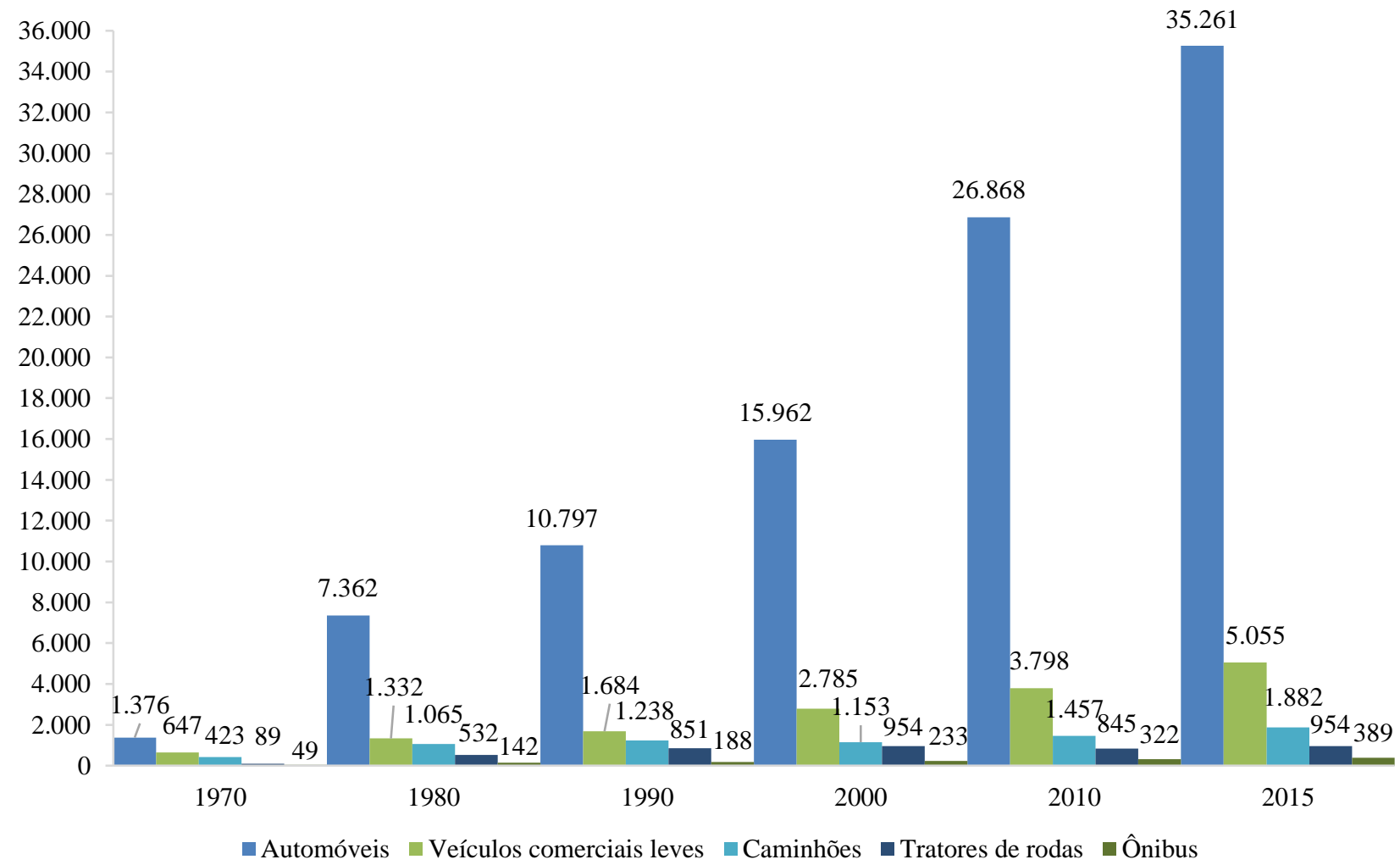

Figura 3 - Composição da frota brasileira de veículos, por década, em Mil unidades. 
Com o aumento do número de veículos licenciados e o crescimento, de modo geral, da frota tanto de automóveis, assim como de tratores, o número de veículos por quilômetro de rodovia, também se elevou. Esse crescimento foi superior a $1.000 \%$ em quatro décadas, o qual passou de 2,3 veículos por quilômetro de rodovia em 1970, para 25,5 veículos por quilômetro no ano de 2015. Isso pode ocorrer devido ao crescimento pouco expressivo na extensão das rodovias brasileiras que são, basicamente, as mesmas da década de 70, e ao aumento expressivo de veículos licenciados (Figura 4).

Além do aumento no volume e na densidade do tráfego de veículos, os limites de velocidade altos, o tipo e a largura da via são fatores associados à ocorrência de acidentes com máquinas agrícolas em vias públicas [25]. Estudos realizados por Harland; Greenan; Rramirez. [10]; Greenan et al. [25]; Costello, Schulman; Mitchell [26], demonstraram que o acréscimo da densidade do tráfego de veículos é o principal fator que contribui para a ocorrência de acidentes, aumentando o risco de colisões com tratores agrícolas.

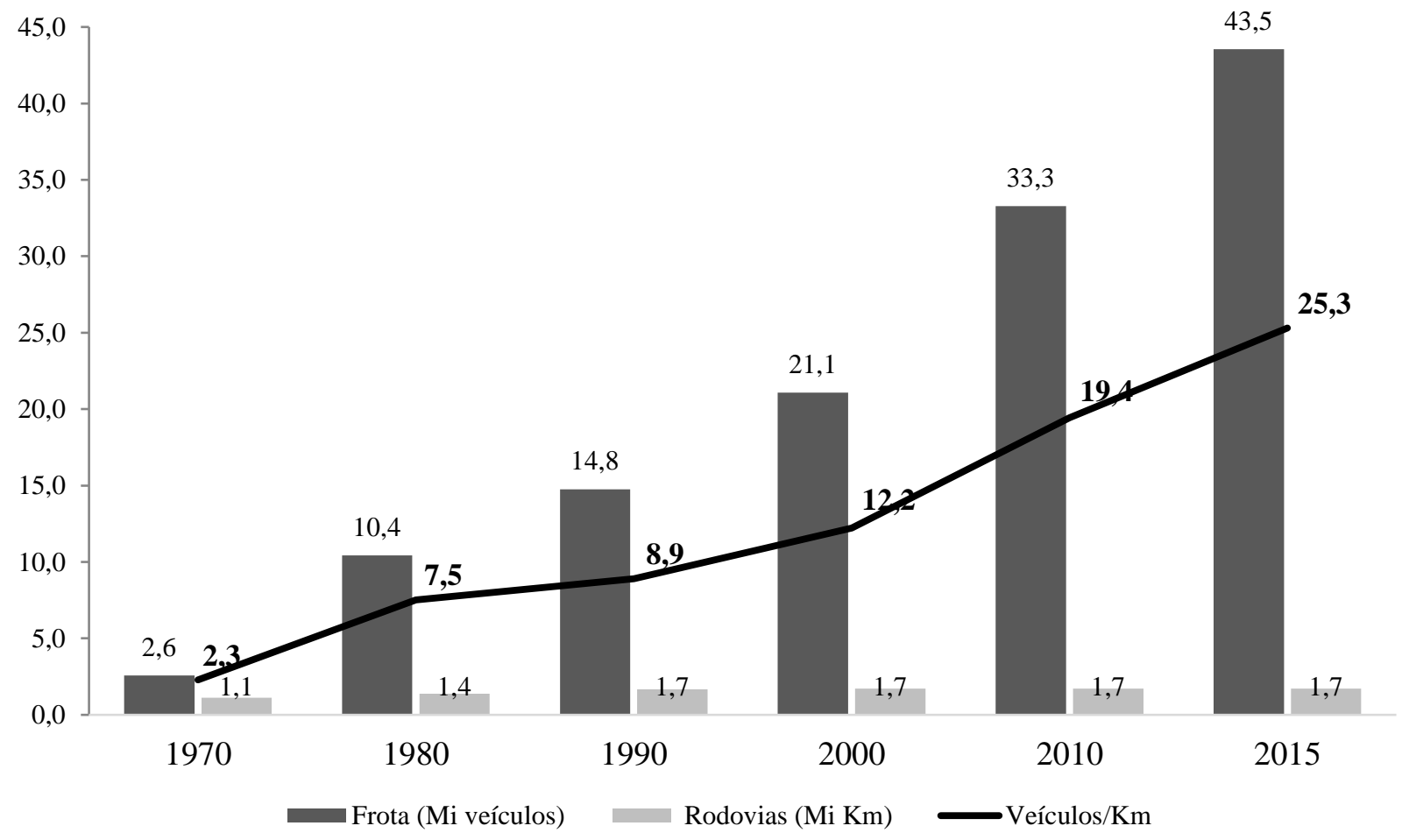

Figura 4 - Evolução do número de veículos, quilômetros de rodovias e veículos por quilômetro de rodovias brasileiras.

Os acidentes com máquinas agrícolas estão se tornando cada vez mais comuns, não só na zona rural, como também em rodovias, devido ao tráfego constante de máquinas agrícolas para mudança de local de trabalho ou para transporte de produtos e insumos [27]. Sendo que pelo menos um em cada três acidentes com máquinas agrícolas em vias públicas ocorrem em zonas urbanas [7, 10, 29].

De acordo com Monteiro e Mota [30] o número de óbitos em acidentes com tratores agrícolas é praticamente equivalente entre os que ocorrem nas propriedades e nas rodovias brasileiras, destacando-se o capotamento e a colisão como os tipos mais comuns de acidentes. Também observaram que determinados tipos de acidentes são restritos ou ocorrem quase que exclusivamente em certos locais. Ainda segundo os mesmos autores, é citada a colisão, como o acidente que ocorre $95 \%$ das vezes nas vias de circulação.

Conforme Gkritza et al. [7] as colisões traseiras em tratores agrícolas demonstraram maior probabilidade de ocorrência de lesões graves ou fatalidades, comparadas a outras formas de colisões. A preocupação com este problema vai além do trabalho no campo com os agricultores, pois atinge todos os usuários das vias públicas. 
É importante destacar que o número de acidentes envolvendo tratores agrícolas, nas vias públicas é menor, comparado aos acidentes apenas entre veículos automotores. Porém, quando se observa a gravidade dos acidentes, os que envolvem tratores apresentam de 5 a 8 vezes mais fatalidades [26, 31-33].

Ressalta-se que na ocorrência de lesões ou fatalidades evidenciadas em colisões envolvendo tratores agrícolas, a severidade nas lesões é cerca de 5 vezes maior nos motoristas dos outros veículos, em comparação ao do trator agrícola, justamente devido a maior rusticidade dessas máquinas [34].

Dados do relatório do CINDS [35], no estado brasileiro de Minas Gerais corroboram com esse número, pois a quantidade de vítimas fatais, devido a acidentes com tratores nas vias públicas do estado, proporcionalmente ao número de ocorrências, foi 4,7 vezes superior que o número de vítimas com acidentes com os demais veículos.

\section{Conclusões}

Houve acréscimo na densidade do tráfego nas rodovias brasileiras. Esta intensificação ocorreu fortemente nos últimos 40 anos, quando passou de 2,3 para 25,5 veículos por quilômetro. Demais estudos demonstram relação entre o aumento da densidade do tráfego e o acréscimo no número de acidentes com máquinas agrícolas em vias públicas não só do Brasil, como de outros países.

\section{Agradecimentos}

Os autores agradecem à Coordenação de Aperfeiçoamento de Pessoal de Nível Superior (CAPES) e ao Conselho Nacional de Desenvolvimento Científico e Tecnológico (CNPQ).

\section{TRAFFIC INTENSIFICATION EVOLUTION AND THE INCIDENCE OF ACCIDENTS WITH AGRICULTURAL TRACTORS IN BRAZILIAN HIGHWAYS}

ABSTRACT: The increasing usage of agricultural machines, especially of tractors, in the search for the increase of the dominating surface, also intensified the propensity to accidents with these machines. Thus, the objective of this study was to calculate the evolution of the number of vehicles per kilometer on the Brazilian highways, from 1970 to 2015 and to interrelate with the accidents involving agricultural tractors, in the public roads. For this study, the Brazilian fleet of conventional vehicles and tractors was considered in this period of 45 years (1970-2015), as well as the extension in kilometers of Brazilian highways. In the last analyzed year (2015), a total of more than 1.72 million kilometers of roads and 43.5 million units of vehicles were observed. Compared to 1.13 million kilometers and 2.5 million vehicles in 1970 , the growth of $52.21 \%$ and 16.8 times, respectively, demonstrate the traffic intensification. At the same time, the circulation of tractors on public roads also increased. This fact, together with the higher speed limits of the roads, the type and the width of the highways, increased the occurrence of accidents in these conditions. Among the accidents, the rear end collisions in tractors are highlighted, with higher indices evidenced. Although the number of accidents is lower, their severity shows 5 to 8 times more fatalities, compared with vehicles. Thus, the evolution was positive, with an increase in traffic intensification on Brazilian highways, but therefore, there is also an increase in the occurrence of accidents with agricultural machinery.

Keywords: Mechanization. Vehicles density. Lighting and signalling. Collisions.

\section{Referências}

[1] ORGANIZAÇÃO MUNDIAL DE SAÚDE. The top 10 causes of death, 2015a. Disponível em: <http://www.who.int/mediacentre/factsheets/fs310/en/> Acesso em: 31 jan. 2017.

[2] CONFEDERAÇÃO NACIONAL DE MUNICÍPIOS - CNM. Mapeamento das mortes no trânsito. Brasília: CNM, 2013. 40 p. ISBN 978-85-99129-72-2. 1

[3] NASCIMENTO, M. F. S. do. Segurança Rodoviária - Legislação e Boas Práticas em Meio Urbano. 2017. 157 p. Dissertação (Mestrado em Engenharia Civil)-Instituto Superior de Engenharia de Lisboa, Lisboa. 2017.

[4] JUNGER, A. P.; DIOTTO, R. S. Sustainability and Public Policy for Contaminants in Brazil. Research, Society and Development, v. 7, n. 6, p. 01-18, 2018

[5] RINALDI, P. C. N. et al. Diagnóstico da potência e torque dos tratores agrícolas fabricados e comercializados no Brasil. Revista Engenharia na Agricultura, v. 23, n. 3, p. 246-256, 2016.

[6] ANFAVEA. Associação Nacional dos Fabricantes de Veículos Automotores. Anuário da indústria automobilística brasileira 2017. São Paulo, 2016. Disponível em: <http://www.anfavea.com.br/estat\%c3\%adsticas.html> Acesso em: 19 jan. 2018

[7] GKRITZA K. et al. An empirical analysis of farm vehicle crash injury severities on Iowa's public road system. Accident Analysis and Prevention, n. 42, p. 1392 1397,2010

[8] SANTOS, V. C. dos; MONTEIRO, L., MACEDO, D. X. S. 2013. Precauções de Segurança durante a condução do trator. Em MONTEIRO, L. \& ALBIERO, D. Segurança na Operação com máquinas agrícolas. Fortaleza: Imprensa Universitária, 2013. 124 p.

[9] MACEDO D. X. S. et al. Caracterização dos acidentes com máquina agrícolas em rodovias federais no estado do Rio Grande do Sul. Ciência Rural, v. 45, n. 1, p. 43-46, 2015.

[10] HARLAND, K. K.; GREENAN, M.; RAMIREZ, M. Not just a rural occurrence: Differences in agricultural equipment crash characteristics by ruralurban crash site and proximity to town. Accident Analysis and Prevention, n. 70, p. 8-13, 2014. 
[11] MACEDO D. X. S. et al. Characterization of accidents involving tractors in Brazilian federal highways in the state of Minas Gerais. African Journal of Agricultural Research, v.10, n. 31, p. 3049-3055, 2015.

[12] MONTEMOR, C.; VELOSO, L.; AREOSA, J. Acidentes com tratores agrícolas e florestais: aprender para prevenir. Sociologia, Revista da Faculdade de Letras da Universidade do Porto, v.30, p.119-143, 2015. Disponível em: <http://www.scielo.mec.pt/pdf/soc/v30/v30a07.pdf>. Acesso em: 15 mar. 2017.

[13] MACEDO D. X. S. et al. Acidentes com tratores agrícolas nas rodovias federais no estado de Goiás. Revista Energia na Agricultura. vol. 31, n. 03, p. 223 $230,2016$.

[14] BRASIL. Código de Trânsito Brasileiro.1. ed. Brasília: DENATRAN, 2008.

[15] GUIMARÃES, L. E.; LEE, F. Levantamento do perfil e avaliação da frota de veículos de passeio brasileira visando racionalizar as emissões de dióxido de carbono. Revista Sociedade \& Natureza, v. 3, n. 22, p. 577-591, 2010.

[16] SINDIPEÇAS. Sindicato Nacional da Indústria de Componentes para Veículos Automotores. Relatório da frota circulante 2017. Disponível em: <https://www.sindipecas.org.br/sindinews/Economia/2017/R_Frota_Circulante_2 017.pdf> Acesso em: 20 mar. 2018.

[17] BELlOCHIO, S. D.C.; ALONÇO, A. D. S.; VARGAS, F. de; OLIVEIRA, M. B. de. Estimativa da frota brasileira de tratores por tempo de uso e vendas. Revista Scientia Agrária, v. 18, n. 3, p. 154-159, 2017.

[18] (GEIPOT) 2001. Anuário do Transporte. Confederação Nacional de Transporte. Estatísticas consolidadas, 2017. Disponível em: <http://anuariodotransporte.cnt.org.br/2017/Rodoviario/1-3-1-1-1-/Malharodovi\%C3\%A1ria-total> Acesso em: 20 de mar. 2018

[19] CONFEDERAÇÃO NACIONAL DE TRANSPORTE. Anuário Estatístico de Transportes 2010-2016. 2017.2 Disponível em: <http://transportes.gov.br/images/BIT_TESTE/Publica\%C3\%A7oes/Sum\%C3\% A1rio_Executivo_AET_-_2010_-_2016.pdf> Acesso em: 20 de mar. 2018.

[20] PEREIRA, L. A. G.; LESSA, S. N. O processo de planejamento e desenvolvimento do transporte rodoviário no Brasil. Caminhos de Geografia, v. 12 , n. 40, p. 26-46, 2011.

[21] GRUPO EXECUTIVO DE INTEGRAÇÃO DA POLÍTICA DE TRANSPORTES. Anuário estatístico de transportes, 1974. Disponível em: $<$ https://ia601202.us.archive.org/28/items/anuariotransp1978br/anuariotransp197 8br.pdf> Acesso em 25 jan. 2017

[22] GRUPO EXECUTIVO DE INTEGRAÇÃO DA POLÍTICA DE TRANSPORTES. Anuário estatístico de transportes, 1985. Disponível em: <https://ia801208.us.archive.org/14/items/anuariotransp1985br/anuariotransp198 5br.pdf> Acesso 25 jan. 2017

[23] SOUZA, A. D. de; ALMEIDA, M. J. de; MAGIROSKI, C.; JESUS, M. J. F. de. Crise mundial de 2008 e adoção de políticas econômicas pelo governo brasileiro. Revista de Ciências Empresariais, v. 18, n. 1, p. 71-89, 2017.

[24] FERREIRA FILHO, J. B.; FELIPE, F. I. Crescimento da produção agrícola e o consumo de tratores de rodas no Brasil entre 1996 - 2005. In: CONGRESSO DA SOCIEDADE BRASILEIRA DE ECONOMIA, ADMINISTRAÇÃO E SOCIOLOGIA RURAL, 45., 2007. Anais... Londrina/PR, 2007. Disponível em: https://www.agrolink.com.br/downloads/88756.pdf. Acesso em: 02 jun. 2017.

[25] GREENAN, M. et al. The effects of roadway characteristics on farm equipment crashes: a geographic information systems approach. Injury Epidemiology, v. 03, n. 31, p. 2-7, 2016.
[26] COSTELLO, T. M.; SCHULMAN, M. D.; MITCHELL, R. E. Risk factors for a farm vehicle public road crash. Accident Analysis and Prevention, n. 41, p. 4247, 2009.

[27] MONTEIRO, L. A. et al. Caracterização dos Acidentes Graves Ocorridos na Zona Rural na Região do Centro Oeste Paulista. XXXIX Congresso Brasileiro de Engenharia Agrícola. Anais... Vitória/ES, 2010.

[28]. Caracterização dos Acidentes Graves Ocorridos na Zona Rural na Região do Centro Oeste Paulista. XXXIX Congresso Brasileiro de Engenharia Agrícola. Anais... Vitória/ES, 2010

[29] PINZKE, S.; LUNDQVIST, P. Slow-movingvehicles in Swedishtraffic. Journal of Agricultural Safety and Health, v. 10, n. 02, p. 121-126, 2004.

[30] MONTEIRO, L.; MOTA, W. A. da. Alerta vermelho no campo. Revista Agriworld, ano 06, v. 21, p. 48-50, 2015 Disponível em:<http://www.lima.ufc.br/arquivos_pdf/20131220132231.pdf> Acesso em: 31 jan. 2017.

[31] AUTORIDADE NACIONAL DE SEGURANÇA RODOVIÁRIA. ANSR 2014. Ficha temática de veículos agrícolas 2004-2013. Disponível em: <http://www.ansr.pt/Estatisticas/FichasTematicas/Documents/2014/FICHA\%20T EMÁTICA\%20-\%20TRACTOR\%20AGRÍCOLAS.pdf> Acesso em: 01 fev. 2017

[32] MONTEIRO, L. Acidentes com máquinas agrícolas matam mais que automóveis e motocicletas. Revista Proteção, v. 12, 2014 Disponível em: <http://www.protecao.com.br/noticias/geral/acidentes_com_maquinas_agricol as_matam_mais_que_automoveis_e_motocicletas/AQjyAAjy/7565> Acesso em: 15 dez. 2016

[33] SANTOS, V. et al. Perigo na Pista. Revista Cultivar, ano 12, n. 139, p. 34-36, 2014

[34] PEEK-ASA, C.; SPRINCE N.L.; WHITTEN P. S. Characteristics of crashes with farm equipment that increase potential for injury. Rural Health Journal; v. 23 n. 04, p. 339-347, 2007.

[35] CENTRO INTEGRADO DE INFORMAÇÕES DE DEFESA SOCIAL CINDS. Diagnóstico de acidentes de trânsito Minas Gerais 2014 - 2015. 2016. Disponível

<http://www.seguranca.mg.gov.br/images/seds_docs/estatisticas/Estatisticas_tran sito/2016.04.15_CINDS_SEDS-

MG_DIAGNOSTICO_DE_ACIDENTES_DE_TRANSITO_MG_2014-

2015.pdf>. Acesso em: Acesso em: 31 jan. 2017. 